\title{
ORIGINAL
}

\section{Detection of glucokinase gene defects in non-obese Japanese children diagnosed with diabetes by school medical examinations}

\author{
Ichiro Yokota $^{1)}$, 2), Maki Moritani ${ }^{1)}$, Kahoru Nishisho ${ }^{2)}$, Tatsuya Miyoshi ${ }^{2)}$, Yumiko Kotani ${ }^{3)}$ and \\ Shoji Kagami ${ }^{3)}$ \\ 1) Institute of Clinical Research, Kagawa National Children's Hospital, Zentsuji, Kagawa 765-8501, Japan \\ ${ }^{2)}$ Department of Pediatrics, Kagawa National Children's Hospital, Zentsuji, Kagawa 765-8501, Japan \\ ${ }^{3)}$ Department of Pediatrics, Tokushima University Graduate School of Medical Sciences, Tokushima, Tokushima 770-8503, Japan
}

\begin{abstract}
We examined children who were diagnosed with asymptomatic type 2 diabetes by school medical examinations to investigate the existence of glucokinase $(G C K)$ gene defects in this group. Among 20 children diagnosed with asymptomatic type 2 diabetes by school medical examinations between 2003 and 2009 at our 2 hospitals, 8 were classified as non-obese type. Among them, we screened 5 children (2 boys and 3 girls; age: 8-13 years) who had mild elevation of fasting plasma glucose (108-134 mg/dL) with slightly high internationally standardized HbA1c levels (6.3-6.9\%) at first close examination. Written informed consent was obtained and all families agreed to participate in this study. We found 4 different mutations (G223S, G81C, S336X and T228M) in 4 of the examined children. The blood glucose control levels had not become worse in any children during the 2-6 years follow-up period. The inheritance of diabetes with GCK gene defect was later confirmed in 1 family. These results suggest that GCK gene defects exist in non-obese children who are diagnosed with asymptomatic diabetes by school medical examinations. Cases of diabetes that are caused by GCK mutations may not be as rare in Japanese subjects as previously described and could be found in patients tentatively diagnosed as type 2 diabetes.
\end{abstract}

Key words: Maturity-onset diabetes of the young (MODY), Glucokinase, Japanese children, School medical examination

GLUCOKINASE is 1 of 4 members of the hexokinase family and it phosphorylates glucose to form glucose-6-phosphate. It is a key regulatory enzyme in pancreatic $\beta$-cells, where it catalyzes the first reaction of the glycolytic pathway and plays a crucial role in regulating insulin secretion [1]. An inactivating heterozygous mutation in the gene that encodes glucokinase (GCK) affects the glucose-sensing system of $\beta$-cells and induces maturity-onset diabetes of the young type 2 (MODY2), which is a form of monogenic diabetes with autosomal dominant inheritance. [2] All inactivating mutations are associated with mild elevation of the fasting plasma glucose (FPG) level. Many GCK gene defects have been reported, mainly in Caucasian tribes

Submitted Feb. 11, 2011; Accepted Jun. 2, 2011 as K11E-062 Released online in J-STAGE as advance publication Jun. 30, 2011 Correspondence to: Ichiro Yokota, M.D., Institute of Clinical Research and Department of Pediatrics, Kagawa National Children's Hospital, 2603 Zentsuji-cho, Zentsuji, Kagawa 7658501, Japan. E-mail: yokotai@kagawasyoni.hosp.go.jp
[3-6]. However, it has been reported that GCK gene mutations are rare in the Japanese; this was according to the studies that mainly examined adult subjects where there were few reports of GCK mutations in Japanese diabetic patients [7, 8]. Similarly, the incidence of GCK gene defects has been reported to be rather low among MODY patients in other Asian countries $[9,10]$.

In Japan, we have a nation-wide diabetes screening system that are targeted at school children and have found a significant number of newly-diagnosed patients with diabetes in this age group [11]. About $30 \%$ of patients with childhood-onset type 2 diabetes are nonobese and have a rather rich family history of this disease, which suggests the involvement of genetic factors for diabetes development [12]. Thus, this group may be a suitable target for the detection of diabetes with single gene defects such as those in the GCK gene.

In this study, we examined children that were clinically diagnosed with type 2 diabetes at our hospitals 
through the diabetes screening system for school children in our region. We found 4 cases of GCK gene defects in 8 non-obese diabetic children, which suggest the existence of the GCK gene defect in Japanese school-age non-obese subjects clinically diagnosed with type 2 diabetes.

\section{Subjects and Methods}

In Japan, a diabetes screening system based on urine glucose testing has been established at schools [11]. In addition, blood examinations for the screening of metabolic abnormalities, such as high glycosylated hemoglobin (HbA1c) level and hypercholesterolemia, have been performed for children in our region who gave consent for these tests. These screening systems function as effective tools for the detection of diabetes in school children without typical symptoms.

Between 2003 and 2009, 20 children who tested positive on these screening tests were finally diagnosed with type 2 diabetes after close examination and follow-up at Kagawa national children's hospital or Tokushima university hospital. All children were negative for the anti-glutamic acid dehydrogenase antibody, which strongly eliminated the migration of type 1 diabetes in this group. The degree of overweight (obesity index) was assessed using percent overweight, which was determined on the basis of Japanese standard body weights for height by age and sex: (actual body weight - standard weight) x 100 / standard weight, and the body weight not exceeding $20 \%$ of the ideal weight was defined as non-obese type [13].

Among these children, 8 were classified as nonobese type at diagnosis. The clinical parameters of these children are in Table 1. HbA1c level, as standardized internationally according to the National Glycohemoglobin Standardization Program (NGSP), was used in this study [14]. Because impaired ability of $\beta$-cells to sense glucose levels appears as mild elevation of FPG and the phenotype of diabetes induced by a GCK gene defect was usually mild in previous reports, we targeted patients 1, 2, 3, 4 and 7 as the candidates for GCK gene analysis according to the following criteria: $\mathrm{FPG} \geq 100 \mathrm{mg} / \mathrm{dL}$ and $\mathrm{HbA} 1 \mathrm{c}<7.4 \%$ (NGSP). Written informed consent for DNA analysis was obtained from these children and their parents by using forms from each hospital and all families agreed to participate in this examination for the affected children.

Genomic DNA was prepared from peripheral white blood cells. To identify mutations in the GCK gene, exons and exon-intron junctions for exon 1 to 10, were amplified by PCR using suitable primer sets designed using the computer (Oligo, ver. 6 software, Molecular Biology Insight, Inc., Cascard, CO, USA), which are available on supplemental Table S1. For exon 1, the alternate exon expressed in the pancreatic $\beta$-cell (exon 1a) was amplified. All amplified PCR products (size, 317 - 633 bp) were prepared with ExoSAP-IT (USB Corporation, $\mathrm{OH}, \mathrm{USA}$ ) and directly sequenced using the BigDye Terminator v.3.1 Cycler Sequencing Kit (Applied Biosystems LLC, Foster City, CA, USA; $\mathrm{AB}$ ) in both directions according to the standard manufacture's method with 3130 genetic Analyzer (AB). All sequences were compared with the GenBank reference sequences (Accession No. NM_000162.3 and NP_000153.1) by using GENETYX ${ }^{\circledR}$ Win ver.8.0, Tokyo, Japan.

Table 1 Clinical manifestation of non-obese children diagnosed with asymptomatic diabetes by school medical examinations

\begin{tabular}{cccccccccc}
\hline $\begin{array}{c}\text { case } \\
\text { number }\end{array}$ & sex & $\begin{array}{c}\text { age at } \\
\text { diagnosis }(\mathrm{y})\end{array}$ & $\begin{array}{c}\text { birth } \\
\text { week(W+d) }\end{array}$ & $\begin{array}{c}\text { birth } \\
\text { weight(g) }\end{array}$ & $\begin{array}{c}\text { obesity } \\
\text { index }(\%)\end{array}$ & $\begin{array}{c}\text { FPG } \\
(\mathrm{mg} / \mathrm{dL})\end{array}$ & $\begin{array}{c}\text { HbA1c* } \\
(\%)\end{array}$ & $\begin{array}{c}\text { family history } \\
\text { of diabetes }\end{array}$ & GCK mutation \\
\hline 1 & M & 8 & $38 \mathrm{~W}+6 \mathrm{~d}$ & 2,552 & +0.5 & 108 & 6.9 & grandparents & G223S \\
2 & $\mathrm{~F}$ & 9 & 39W+5d & 3,294 & +6.9 & 112 & 6.3 & mother & G81C \\
3 & M & 11 & $41 \mathrm{~W}+0 \mathrm{~d}$ & 2,934 & -15.0 & 132 & 6.6 & grandmother & S336X \\
4 & F & 12 & $38 \mathrm{~W}+0 \mathrm{~d}$ & 2,992 & +7.4 & 113 & 6.8 & grandmother, father & none \\
5 & F & 12 & na & na & +13.3 & 111 & 7.9 & mother & nd \\
6 & F & 12 & $41 \mathrm{~W}+0 \mathrm{~d}$ & 2,810 & +6.1 & 86 & 5.6 & none & nd \\
7 & F & 13 & $40 \mathrm{~W}+0 \mathrm{~d}$ & 2,498 & -1.9 & 134 & 6.8 & father & T228M \\
8 & F & 14 & na & na & +16.1 & 149 & 10.2 & mother & nd \\
\hline
\end{tabular}

All clinical data were collected at first visit to our hospitals. ${ }^{*} \mathrm{HbA} 1 \mathrm{c}$ value standardized internationally according to National Glycohemoglobin Standardization Program is used. nd, not done; na, not available 


\section{Results}

By direct sequencing of the GCK gene (exons 1 - 10) in 5 children with non-obese diabetes, 4 different mutations were identified, which changed the amino acid residues or introduced stop codon. Amino acid residues are numbered as in the $\beta$-cell form of GCK. Numbering is based on +1 begins the $\mathrm{A}$ of the major start codon of exon $1 \mathrm{a}$, the alternate exon present in the pancreatic isoform. All these 4 mutations were confirmed by 3 repeated analyses in both forward and reverse directions. The absence of mutations in the wild type $G C K$ gene was confirmed in 100 unrelated non-diabetic control individuals and either Japanese SNP (JSNP) (http:// snp.ims.u-tokyo.ac.jp/) or dbSNP databases (http:// www.ncbi.nlm.nih.gov/projects/SNP/).

The heterozygous $\mathrm{G}$ to A substitution at position 667 in exon 6, which introduced a glycine to serine change at position 223 (G223S), and which had been previously reported in an Italian family [5] was found in case 1 . He visited a clinic because of a weak positive (+/-) result in a urine glucose test at the age of 8 and was then referred to our hospital. He was not obese (obesity index $+0.5 \%$ ) and his HbA1c level was $6.9 \%$. The oral glucose tolerance test (OGTT) showed mild elevation of FPG (108 mg/dL) considering his age. The repeated OGTT, 1 year later, showed a similar pattern (Table 2). During 2 years of follow-up without medication, he was continuously non-obese and his HbA1c level ranged between $6.6 \%$ and $6.9 \%$. His father had died and his mother did not consent to have her DNA examined.

The heterozygous $\mathrm{G}$ to $\mathrm{T}$ substitution at position 241 in exon 3, which introduced a glycine to cysteine change at position 81 (G81C) in the MgATP binding site of glucokinase was found in case 2. She visited our hospital because of a weak positive (+/-) result in a urine glucose test at the age of 9 . She was not obese (obesity index $+6 \%$ ) and her HbA1c level was $6.3 \%$. OGTT showed a mild elevation of FPG (112 mg/dL) (Table 2). The repeated OGTT 1 year later showed similar results and the elevation of FPG level to over $126 \mathrm{mg} / \mathrm{dL}$ and HbA1c value to over 6.5\% during follow-up tests led to the diagnosis of diabetes. During 6 years of follow-up without medication, her HbA1c value ranged between $6.2 \%$ and $6.6 \%$ and had not worse significantly despite mild progression of obesity during puberty (up to $+21 \%$ ). During the follow-up of case 2, the patient's mother was found to have mild diabetes and was treated with a $\alpha$-glucosidase inhibitor $(\alpha-G I)$ at another clinic. DNA examination of the mother showed that she had same mutation in the GCK

Table 2 Result of oral glucose tolerance test (1.75g/kg)

\begin{tabular}{|c|c|c|c|c|c|c|c|c|}
\hline \multirow{2}{*}{$\begin{array}{c}\text { case } \\
\text { number }\end{array}$} & \multirow{2}{*}{$\begin{array}{c}G C K \\
\text { mutation }\end{array}$} & \multirow{2}{*}{$\begin{array}{c}\text { age at } \\
\text { examination (y) }\end{array}$} & & \multicolumn{5}{|c|}{ time after glucose loading (min) } \\
\hline & & & & 0 & 30 & 60 & 90 & 120 \\
\hline \multirow{4}{*}{1} & \multirow{4}{*}{ G223S } & \multirow{2}{*}{8} & PG (mg/dL) & 108 & 199 & 207 & 225 & 248 \\
\hline & & & IRI $(\mu \mathrm{U} / \mathrm{mL})$ & 2.4 & 19 & nd & nd & 40.5 \\
\hline & & \multirow{2}{*}{9} & PG (mg/dL) & 128 & 227 & 213 & 201 & 179 \\
\hline & & & IRI $(\mu \mathrm{U} / \mathrm{mL})$ & 7 & 17.2 & 35.6 & 36.3 & 26.4 \\
\hline \multirow{4}{*}{2} & \multirow{4}{*}{ G81C } & \multirow{2}{*}{9} & PG (mg/dL) & 112 & 178 & 219 & 203 & 199 \\
\hline & & & IRI $(\mu \mathrm{U} / \mathrm{mL})$ & 6.2 & 23.8 & 38.4 & 31.3 & 39.8 \\
\hline & & \multirow{2}{*}{10} & PG (mg/dL) & 120 & 202 & 185 & 192 & 164 \\
\hline & & & IRI $(\mu \mathrm{U} / \mathrm{mL})$ & 5.3 & 41.6 & 49.4 & 45.7 & 46.6 \\
\hline \multirow{4}{*}{3} & \multirow{4}{*}{ S336X } & \multirow{2}{*}{11} & PG (mg/dL) & 132 & 214 & 172 & 161 & 165 \\
\hline & & & IRI $(\mu \mathrm{U} / \mathrm{mL})$ & 7.2 & 40.5 & 15.7 & 17.3 & 15 \\
\hline & & \multirow{2}{*}{12} & PG (mg/dL) & 136 & 232 & 225 & 202 & 191 \\
\hline & & & IRI $(\mu \mathrm{U} / \mathrm{mL})$ & 10.1 & 102.2 & 87.9 & 102.9 & 72.5 \\
\hline \multirow{2}{*}{7} & \multirow{2}{*}{ T228M } & \multirow{2}{*}{13} & PG (mg/dL) & 134 & 253 & 271 & 235 & 242 \\
\hline & & & IRI $(\mu \mathrm{U} / \mathrm{mL})$ & 10 & 78 & 92.5 & 71.6 & 76.6 \\
\hline \multirow{2}{*}{4} & \multirow{2}{*}{ absent } & \multirow{2}{*}{12} & PG (mg/dL) & 113 & 190 & 226 & 212 & 206 \\
\hline & & & IRI $(\mu \mathrm{U} / \mathrm{mL})$ & 6.1 & 19.2 & 32 & 23.1 & 25.3 \\
\hline \multirow{2}{*}{6} & \multirow{2}{*}{ nd } & \multirow{2}{*}{12} & PG (mg/dL) & 86 & 184 & 238 & nd & 239 \\
\hline & & & IRI $(\mu \mathrm{U} / \mathrm{mL})$ & 2.8 & 31.9 & 61.5 & nd & 147.2 \\
\hline
\end{tabular}

OGTT was not performed in case 5, 8 .

PG: plasma glucose IRI: immunoreactive insulin nd: not done 
gene. Her HbA1c level was 6.8\% and FPG level was $140 \mathrm{mg} / \mathrm{dL}$ at the time of DNA examination.

The heterozygous $\mathrm{C}$ to $\mathrm{T}$ substitution at position 1007 in exon 8, which introduced a stop codon (S336X), was found in case 3 . He was found to have a slightly high HbA1c level (6.3\%) at a school medical examination at the age of 11 . When he visited our hospital, he was lean (obesity index -15.4\%) and his HbA1c level was 6.8\%. The OGTT showed a rather high FPG level (132mg/ $\mathrm{dL}$ ) but relatively mild elevation of the PG level after glucose loading due to compensated insulin secretion following the elevation of PG. One year later, OGTT showed a similar PG pattern with an elevated insulin level, probably due to the increased insulin resistance because of the progression of puberty (Table 2). He was treated with $\alpha$-GI during a short period after diagnosis and then followed-up with diet and exercise therapy. For 3 years, he remained lean and his HbA1c level ranged between $5.8 \%$ and $6.8 \%$. His father had died and his mother did not consent to DNA examination.

The heterozygous $\mathrm{C}$ to $\mathrm{T}$ substitution at position 683 in exon 7, which introduced a threonine to methionine change at position 228 (T228M), and which has been previously reported in a Caucasian family [16], was found in case 7 . She also visited our hospital because of positive urine glucose test at the age of 13 . She was also not obese (obesity index $-1.9 \%$ ) and her HbA1c level was $6.8 \%$. The OGTT also showed mild elevation of FPG $(134 \mathrm{mg} / \mathrm{dL})$ and exhibited a similar pattern after glucose loading (Table 2). She had a relatively high HbA1c level during a 2-year follow-up with diet and exercise therapy (6.8 7.4\%), although it had not become worse. Her father has been found to have mild diabetes at another clinic, but he did not consent to DNA examination.

\section{Discussion}

In the present study, we found that GCK gene defects exist among Japanese children that were diagnosed with asymptomatic diabetes by school medical examinations, particularly among non-obese subjects with elevated FPG level and mild diabetes.

Among Caucasian tribes, the GCK gene defect is known to be important in the cause of MODY, so called MODY2, and many mutations have been reported from several European ethnic origins [2-6]. In contrast, adult-based sample collection in Japan suggested that mutation in GCK is rare in MODY, and some cases have been reported in pediatric departments [7, 8]. However, adult subjects are largely affected by acquired factors, such as lifestyle, and compared with Caucasians, many adult Japanese diabetic subjects have rather poor insulin secretion and are relatively non-obese. This might make the distinction of non-obese diabetes, originated from a single-gene defect, difficult in an adult population. Furthermore, because the clinical degree of diabetes is usually mild in patients with GCK gene defects, it is often difficult to demonstrate the family history of diabetes, as in our cases. In European countries, it is also suggested that the age and clinical selection criteria of the target population plays a role in the prevalence of detection of CCK mutations [2].

Among Japanese type 2 diabetic children, non-obese subjects were the minority, but they usually have poor insulin secretion and apparent family history, which suggests that they are good candidates for the detection of the gene abnormalities that affect insulin secretion such as MODY gene. Therefore, we targeted our analysis to this group with additional selection criteria, elevated FPG and mild diabetes which are suitable for the selection of GCK defects. It is certain that we could not estimate the incidence of the GCK gene defect among diabetic subjects using only this hospital-based study. However, our results suggest that close observation of children that are diagnosed with non-obese type 2 diabetes may lead to the detection of GCK gene defects in many cases, even in Japan.

We identified 4 different heterozygous mutations, G223S, G81C, S336X and T228M, in the GCK genes of non-obese Japanese children who were diagnosed with asymptomatic diabetes by school medical examinations. Among them, G81C was newly identified. The G223S, S336X and T228M mutations had been reported in several European ethnic origins previously $[2,5,16]$.

In one case, the G81C mutation was inherited from a mother who was later also diagnosed with mild diabetes. In addition, other previous studies had reported G81S, G80S, and G80A mutations as the origin of diabetes, suggesting the importance of this region for the function of glucokinase [5, 15, 17]. Thus, we believe that this GCK mutation caused diabetes in both the mother and her daughter. In case 3 , although we could not analyze the inheritance of S336X because of the lack of consent from his mother, this nonsense mutation most likely changed the glucose-sensing level in pancreatic $\beta$-cells and originated his diabetes. In case 2 , 
the inheritance of diabetes through a GCK gene defect became apparent following a school medical examination for children. This may suggest the importance of performing a family search starting from an affected child as part of the protocol for studies of diabetes caused by an inherited single-gene defect, especially cases with mild symptoms, such as those caused by $G C K$ defects. Because determining the genetic causes of diabetes will provide useful information for the prediction of the prognosis and for deciding on the therapeutic method, the discovery of inheritance is meaningful for both children and their undiagnosed affected family members.

Among the 5 children in which we examined the GCK gene, we did not find any mutations in case 4 . During 3 years of follow-up, her HbA1c value had not become worse. There was no significant difference in the clinical data between this case and the other 4 cases with GCK mutations.

Although the number of subjects in our study is small, the percentage of non-obese subjects was relatively high compared with that in a previous study that included all patients diagnosed with or without school medical examinations [12]. This may suggest that obese subjects tend to avoid further medical examination until the appearance of nasty subjective symptoms such as excessive urination. It has been reported that the percentage of type 2 diabetic children having serious psychological or domestic problems is higher in obese subjects.

In summary, we identified 4 different mutations in non-obese Japanese children who were diagnosed with diabetes by school medical examinations. The FPG level and obesity index are useful tools to identify GCK mutations in these subjects who are clinically diagnosed with type 2 diabetes, and cases of diabetes that are caused by GCK mutations may not be rare in Japanese subjects as previously described.

\section{Acknowledgement}

This study was supported by a Grant-in-Aid for Scientific Research (C) (Grant No. 22590997) from the Japan Society for the Promotion of Science. The authors have no conflict of interest to disclose in relation to the findings contained in this manuscript. We sincerely thank our patients for donating blood samples and participating in this study.

\begin{tabular}{|c|c|c|c|c|c|}
\hline $\begin{array}{c}\text { gene } \\
\text { symbol }\end{array}$ & region & primer sequence & location & $\begin{array}{l}\text { amplicon } \\
\text { size (bp) }\end{array}$ & $\begin{array}{l}\text { annealing } \\
\text { temperature }\end{array}$ \\
\hline \multirow{22}{*}{ GCK } & \multirow[t]{2}{*}{ Exon 1.a } & Forward 5'- TGGTCACCATGACAACCACA -3' & 5'UTR & \multirow{2}{*}{633} & \multirow{2}{*}{$58{ }^{\circ} \mathrm{C}$} \\
\hline & & Reverse 5'- AGCAAACACTCCCAGAATGC -3' & intron 1 & & \\
\hline & \multirow[t]{2}{*}{ Exon 1.b } & Forward 5'- TGTCAACTGTTACCCACATG -3' & intron 1 & \multirow{2}{*}{405} & \multirow{2}{*}{$58{ }^{\circ} \mathrm{C}$} \\
\hline & & Reverse 5'- CCCAGCCTTAGTTTTGGTAA -3' & intron 1 & & \\
\hline & \multirow[t]{2}{*}{ Exon 1.c } & Forward 5'- TCTCCСАCTGCTATCCAAC -3' & intron 1 & \multirow{2}{*}{327} & \multirow{2}{*}{$58^{\circ} \mathrm{C}$} \\
\hline & & Reverse 5'- CAGGCTTGGTGAAAGCGAT -3' & intron 1 & & \\
\hline & \multirow[t]{2}{*}{ Exon 2} & Forward 5'- GTTTGAGAAGATGGGTCATC -3' & intron 1 & \multirow{2}{*}{476} & \multirow{2}{*}{$58{ }^{\circ} \mathrm{C}$} \\
\hline & & Reverse 5'- AAGTCGAGGACTTCATTGCT -3' & intron 2 & & \\
\hline & \multirow[t]{2}{*}{ Exon 3} & Forward 5'- TCTTTGTAATATCCGGGCTCA -3' & intron 2 & \multirow{2}{*}{425} & \multirow{2}{*}{$58^{\circ} \mathrm{C}$} \\
\hline & & Reverse 5'- CATGTTGGCCAGTCCTGTT -3' & intron 3 & & \\
\hline & \multirow[t]{2}{*}{ Exon 4} & Forward 5'- TTGCAGTGTCCCTGAGGAAT -3' & intron 3 & \multirow{2}{*}{301} & \multirow{2}{*}{$58^{\circ} \mathrm{C}$} \\
\hline & & Reverse 5'- GGGCTACATTTGAAGGCAG -3' & intron 4 & & \\
\hline & \multirow[t]{2}{*}{ Exon 5.6} & Forward 5'- TAGCACCCTGCCTCCAGTA -3' & intron 4 & \multirow{2}{*}{485} & \multirow{2}{*}{$58{ }^{\circ} \mathrm{C}$} \\
\hline & & Reverse 5'- CAGGCTCTGCTCTGACATC -3' & intron 6 & & \\
\hline & \multirow[t]{2}{*}{ Exon 7} & Forward 5'- CCATTGTTCCAGACAAAGCA -3' & intron 6 & \multirow{2}{*}{400} & \multirow{2}{*}{$58{ }^{\circ} \mathrm{C}$} \\
\hline & & Reverse 5'- CAAGCCCATTATCTGCAATG -3' & intron 7 & & \\
\hline & \multirow[t]{2}{*}{ Exon 8} & Forward 5'- AGGGAAAGACGTGAACCAG -3' & intron 7 & \multirow{2}{*}{392} & \multirow{2}{*}{$58^{\circ} \mathrm{C}$} \\
\hline & & Reverse 5'- TCGCCCTGAGACCAAGTCT -3' & intron 8 & & \\
\hline & \multirow[t]{2}{*}{ Exon 9} & Forward 5'- ACTGTCGGAGCGACACTCA -3' & intron 8 & \multirow{2}{*}{317} & \multirow{2}{*}{$58^{\circ} \mathrm{C}$} \\
\hline & & Reverse 5'- CTACGAAATCTTGGAGCTTG -3' & intron 9 & & \\
\hline & \multirow[t]{2}{*}{ Exon 10} & Forward 5'- CAAGCTCCAAGATTTCGTAG -3' & intron 9 & \multirow{2}{*}{557} & \multirow{2}{*}{$58^{\circ} \mathrm{C}$} \\
\hline & & Reverse 5'- GGAAATTGATTCCAGCGAGA -3' & exon 10 & & \\
\hline
\end{tabular}




\section{References}

1. Matschinsky FM (2002) Regulation of pancreatic betacell glucokinase: from basics to therapeutics. Diabetes 51: S394-S404.

2. Osbak KK, Colclough K, Saint-Martin C, Beer NL, Bellanné-Chantelot C, Ellard S, Gloyn AL (2009) Update on mutations in glucokinase (GCK), which cause maturity-onset diabetes of the young, permanent neonatal diabetes, and hyperinsulinemic hypoglycemia. Hum Mutat 30: 1512-1526.

3. Froguel P, Zouali H, Vionnet N, Velho G, Vaxillaire M, Sun F, Lesage S, Stoffel M, Takeda J, Passa P, Permutt MA, Beckmann JS, Bell Gi, Cohen D (1993) Familial hyperglycaemia due to mutations in glucokinase. Definition of a subtype of diabetes mellitus. $N$ Engl $J$ Med 328: 697-702.

4. Thomson KL, Gloyn AL, Colclough K, Batten M, Allen LI, Beards F, Hattersley AT, Ellard S (2003) Identification of 21 novel glucokinase (GCK) mutations in UK and European Caucasians with maturity-onset diabetes of the young (MODY). Hum Mutat 22: 417.

5. Massa O, Meschi F, Cuesta-Munoz A, Caumo A, Cerutti F, Toni S, Cherubini V, Guazzarotti L, Sulli N, Matschinsky FM, Lorini R, Iafusco D, Barbetti F; Italian Society of Paediatic Endocrinology and Diabetes (SIEDP) (2001) High prevalence of glucokinase mutations in Italian children with MODY. Influence on glucose tolerance, first-phase insulin response, insulin sensitivity and BMI. Diabetologia 44: 898-905.

6. Pruhova S, Dusatkova P, Sumnik Z, Kolouskova S, Pedersen O, Hansen T, Cinek O, Lebl J (2010) Glucokinase diabetes in 103 families from a countrybased study in the Czech Republic: geographically restricted distribution of two prevalent GCK mutations. Pediatr Diabetes 11: 529-535.

7. Nanao K, Miyamoto J, Higuchi A, Anzo M, Takahashi I, Kogayashi H, Hasegawa Y (2001) A family with diabetes caused by glucokinase deficiency: Relathionship between the onset and life style. Clin Pediatr Endocrinol 10: 171.

8. Jo W, Fujieda K, Tajima T (2010) A novel mutation of the glucokinase gene in maturity-onset diabetes of the young type 2 (MODY2). Clin Pediatr Endocrinol 19: 45-46.

9. Xu JY, Dan QH, Chan V, Wat NM, Tam S, Tiu SC, Lee KF, Siu SC, Tsang MW, Fung LM, Chan KW, Lam KS (2005) Genetic and clinical characteristics of maturity- onset diabetes of the young in Chinese patients. Eur $J$ Hum Genet 13: 422-427.

10. Hwang JS, Shin CH, Yang SW, Jung SY, Huh N (2006) Genetic and clinical characteristics of Korean maturityonset diabetes of the young (MODY) patients. Diabetes Res Clin Pract 74: 75-81.

11. Urakami T, Morimoto S, Nitadori Y, Harada K, Owada M, Kitagawa T (2007) Urine glucose screening program at schools in Japan to detect children with diabetes and its outcome-incidence and clinical characteristics of childhood type 2 diabetes in Japan. Pediatr Res 61: 141-145.

12. Sugihara S, Sasaki N, Amemiya S, Kohno H, Tanaka T, Matsuura N (2008) Analysis of weight at birth and at diagnosis of childhood-onset type 2 diabetes mellitus in Japan. Pediatr Diabetes 9: 285-290.

13. Murata M (2003) Assessment of obesity: growth curve and corpulence degree. Jpn J Pediatr 56: 2315-2326 (in Japanese).

14. Seino Y, Nanjo K, Tajima N, Kadowaki T, Kashiwagi A, Araki E, Ito C, Inagaki N, Iwamoto Y, Kasuga M, Hanafusa T, Haneda M, Ueki K. (2010) Report of the Committee on the classification and diagnostic criteria of diabetes mellitus. The Committee of the Japan Diabetes Society on the diagnostic criteria of diabetes mellitus. Diabetology International 1: 2-20.

15. Guazzini B, Gaffi D, Mainieri D, Multari G, Cordera R, Bertolini S, Pozza G, Meschi F, Barbetti F (1998) Three novel missense mutations in the glucokinase gene (G80S; E221K; G227C) in Italian subjects with maturity-onset diabetes of the young (MODY). Hum Mutat 12: 136.

16. Stoffel M, Froguel P, Takeda J, Zouali H, Vionnet N, Nishi S, Weber IT, Harrison RW, Pilkis SJ, Lesage S, Vaxillaire M, Velho G, Sun F, Iris F, Passa Ph, Cohen D, Bell GI. (1992) Human glucokinase gene: isolation, characterization, and identification of two missense mutations linked to early-onset non-insulin-dependent (type 2) diabetes mellitus. Proc Natl Acad Sci U S A 89: 7698-7702.

17. Velho G, Blanché H, Vaxillaire M, Bellanné-Chantelot C, Pardini VC, Timsit J, Passa P, Deschamps I, Robert JJ, Weber IT, Marotta D, Pilkis SJ, Lipkind GM, Bell GI, Froguel P (1997) Identification of 14 new glucokinase mutations and description of the clinical profile of 42 MODY-2 families. Diabetologia 40: 217-224. 